\title{
Magnetic retraction for NOTES transvaginal cholecystectomy
}

\author{
Santiago Horgan - Yoav Mintz • Garth R. Jacobsen • Bryan J. Sandler • \\ John P. Cullen · Adam Spivack - David W. Easter • Alana Chock • \\ Michelle K. Savu - Sonia Ramamoorthy $\cdot$ Julie Bosia $\cdot$ Sanjay Agarwal · \\ Emily Lukacz • Emily Whitcomb - Thomas Savides • Mark A. Talamini
}

Received: 2 October 2008/Accepted: 14 March 2009/Published online: 23 February 2010

(C) The Author(s) 2010. This article is published with open access at Springerlink.com

\begin{abstract}
Background Natural orifice translumenal endoscopic surgery (NOTES) has the potential to decrease the burden of an operation on a patient. Limitations of the endoscopic platform require innovative solutions to provide retraction and create an operation comparable with the gold standard, laparoscopic cholecystectomy.

Methods Four patients underwent transvaginal cholecystectomy. All procedures were performed under laparoscopic vision to ensure safety. The endoscope and a long articulating RealHand instrument were placed via a $15-\mathrm{mm}$ vaginal trocar. A magnetic retraction system was used to retract the gallbladder safely. Laparoscopic clips were used to ligate the cystic duct and artery. All four gallbladders were successfully removed. No complications occurred. The mean operating time was $102 \mathrm{~min}$.

Results All four procedures were completed without complications. The four patients all were discharged shortly after surgery and reported normal sexual activity without pain.
\end{abstract}

Conclusions Transvaginal cholecystectomy can be completed safely using current technology. Further studies are needed to determine the safety of the procedure and to determine whether it confers any benefits other than cosmesis.

Keywords Cholecystectomy · Magnets - NOTES · Retraction · Transvaginal

Disclosures Santiago Horgan,Yoav Mintz, Garth R. Jacobsen, Bryan J. Sandler, John P. Cullen, Adam Spivack, David W. Easter, Alana Chock, Michelle K. Savu, Sonia Ramamoorthy, Julie Bosia, Sanjay Agarwal, Emily Lukacz, Emily Whitcomb, Thomas Savides, and Mark A. Talamini have no conflicts of interest or financial ties to disclose.

Open Access This article is distributed under the terms of the Creative Commons Attribution Noncommercial License which permits any noncommercial use, distribution, and reproduction in any medium, provided the original author(s) and source are credited.

Electronic supplementary material The online version of this article (doi:10.1007/s00464-010-0954-9) contains supplementary material, which is available to authorized users.

S. Horgan · Y. Mintz · G. R. Jacobsen .

B. J. Sandler · J. P. Cullen · A. Spivack $(\varangle)$.

D. W. Easter - A. Chock - M. K. Savu - S. Ramamoorthy ·

J. Bosia - S. Agarwal - E. Lukacz - E. Whitcomb - T. Savides .

M. A. Talamini

University of California, San Diego, CA, USA

e-mail: aspivack@ucsd.edu 